\title{
Relationship between glucagon-like peptide-1 receptor gene polymorphism and bone mineral density in postmenopausal women in Shanghai
}

\author{
Lizhi Zhang ${ }^{1}$, Jinwei He ${ }^{2}$, Xiang Sun ${ }^{3}$, Xian Luo ${ }^{1}$, Juli Zeng ${ }^{1}$, Wufeng He ${ }^{1}$, Xiaohui Liu ${ }^{1}$, Bo Feng ${ }^{1}$ \\ ${ }^{1}$ Department of Endocrinology, Shanghai East Hospital, Tongji University School of Medicine, Shanghai, China; ${ }^{2}$ Department of Osteoporosis \\ and Bone Disease, Shanghai Jiao Tong University Affiliated Sixth People's Hospital, Shanghai, China; ${ }^{3}$ Shanghai Institute of Technology, Shanghai, \\ China \\ Contributions: (I) Conception and design: L Zhang, B Feng; (II) Administrative support: B Feng; (III) Provision of study materials or patients: J He; \\ (IV) Collection and assembly of data: J He, X Luo; (V) Data analysis and interpretation: X Sun, J Zeng, W He, X Liu; (VI) Manuscript writing: All \\ authors; (VII) Final approval of manuscript: All authors. \\ Correspondence to: Bo Feng. Department of Endocrinology, Shanghai East Hospital, Tongji University School of Medicine, Shanghai 200120, China. \\ Email: fengbodfyy@tongji.edu.cn.
}

Background: Glucagon-like peptide-1 receptor (GLP-1R) agonists are able to inhibit bone resorption to
a certain extent and improve bone formation. GLP-1R single nucleotide polymorphism (SNP) is related to
its activity, but the relationship between GLP-1R SNP and osteoporosis in postmenopausal women was still
unclear. This study was to investigate the association between GLP-1R SNP and bone mineral density (BMD)
in postmenopausal women in Shanghai. Methods: Eight SNPs of GLP-1R were detected (rs3765467, rs1042044, rs2268657, rs6923761, rs2268641, rs2295006, rs4714210 and rs10305420) in 884 postmenopausal women in Shanghai. The correlation between GLP-1R SNP and BMD was further assessed.

Results: The A/A genotype of rs2295006 was negatively related to lumbar vertebrae $1-4 \mathrm{BMD}(\mathrm{P}<0.05)$. Allele A was negatively related to hip BMD $(\mathrm{P}<0.05)$. There was a negative correlation between haplotype CGAGCCA and lumbar BMD, and a positive correlation between haplotype CGGGCTA and lumbar BMD. The remaining seven GLP-1R SNPs had no relationship with BMD.

Conclusions: The rs2295006 of GLP-1R is related to the BMD of postmenopausal women in Shanghai, China.

Keywords: Osteoporosis; glucagon-like peptide-1 receptor (GLP-1R); single-nucleotide polymorphisms; polymorphism; haplotypes; bone mineral density (BMD)

Submitted Oct 19, 2019. Accepted for publication Apr 07, 2020.

doi: 10.21037/apm-19-396

View this article at: http://dx.doi.org/10.21037/apm-19-396

\section{Introduction}

Osteoporosis is a systemic bone disease characterized by low bone mass, destruction of bone microstructure, increased bone fragility, and being prone to fractures (1). Bone mineral density (BMD) has been the most common parameter in the diagnosis of osteoporosis, but it is also affected by some genetic factors. There is evidence showing that genetic factors account for $60-80 \%$ of BMD variability (2).
Multiple studies have shown that osteoporosis syndrome is a complex polygenic disease which is the result of a combination of genetic and environmental factors (3).

Postmenopausal osteoporosis is a common disease associated with aging and significantly affects the quality of life of postmenopausal women. Diabetic osteoporosis (DOP) is also a clinically concerned disease because of its high prevalence and disability rate (4-6). It has been shown 
that the bone microenvironment and bone metabolism have changed significantly in the diabetic patients $(7,8)$. These include a large reduction in bone mineral content, a poor balance of bone turnover, a significant reduction in bone density, and other clinical symptoms of osteoporosis (9-11).

Diabetes can affect bone metabolism in a variety of ways (12-14). There is evidence showing that some commonly used glucose-lowering drugs, such as glucagonlike peptide-1 receptor (GLP-1R) agonists, can inhibit the bone resorption and improve the bone formation (15-18). Glucagon-like peptide-1 (GLP-1) is an endogenous peptide hormone and can bind to GLP-1R, exerting glucosedependent glucose-lowering effects (19).

In the GLP-1R knockout (GLP-1 $\mathrm{R}^{-/}$) mouse model (16), Yamada et al. found the cortical BMD decreased significantly, and the bone fragility increased markedly, which increased the risk for osteoporosis. Moreover, GLP$1 \mathrm{R}^{-/-}$mice displayed significantly increased bone resorption. The study of Stojanovic et al. indicated a close relationship between osteoporosis and hyperlipidemia (20). NucheBerenguer et al. found GLP-1 could reverse the reduction in bone mass secondary to hyperlipidemia (21).

GLP-1R is encoded by the GLP-1R gene mapped on chromosome 6 (6p21) of human genome (22). The gene polymorphism varies among races and different individuals may have different genotypes. A total of 33 single nucleotide polymorphisms (SNPs) have been identified in the GLP-1Rgene of CHB (Han from Beijing) population in the second phase HapMap data (http://www.hapmap.org).

SNP mainly refers to a DNA sequence polymorphism caused by a single nucleotide variation at the genomic level. To date, no study has been undertaken to investigate the relationship between GLP-1R SNP and osteoporosis in the postmenopausal women. After reviewing literature, eight SNPs of GLP-1R gene (rs3765467, rs1042044, rs2268657, rs6923761, rs2268641, rs2295006, rs4714210 and rs10305420) were detected in the postmenopausal women in Shanghai using the established database and the relationship between GLP-1R SNP and BMD was further assessed. Our findings may provide evidence on the effects of GLP-1 on the osteoporosis and DOP.

The study was approved by the Ethics Committee of the Sixth People's Hospital, Shanghai Jiaotong University [2014-KY-001(K)]. Han Chinese women who were treated in the Department of Osteoporosis and Osteopathy of the Sixth People's Hospital were included. The inclusion criteria were as follows: (I) women had natural menopause for more than 1 year; (II) women did not receive anti-osteoporotic treatment (except calcium and vitamin D supplement); (III) there was no disease affecting bone metabolism.

In this study, the $\mathrm{iMLDR}^{\circledR}$ multiple SNP typing (23) (Shanghai Tianhao Biotechnology Co., Ltd) was used detect eight SNPs in 884 subjects.

Postmenopausal women received dual-energy X-ray absorptiometry (GE-LUNAR Prodigy USA) for the measurement of lumbar vertebrae 1-4 (L1-4), left femoral neck (femoral neck) and total hip (total hip) BMD $\left(\mathrm{g} / \mathrm{cm}^{2}\right)$. For the quality control, the instrument was standardized once daily. The coefficient of variation $(\mathrm{CV})$ of the lumbar vertebrae, femoral neck and total hip BMD measurements was $1.39 \%, 2.22 \%$ and $0.70 \%$, respectively (24).

\section{Methods}

\section{Detection of SNPs}

The selection of tag SNP is based on the International Human Genome Haplotype Program (International HapMap Project. http://www.Hapmap.org/cgi-perl/ gbrowse/hapmap3_B36), and the criteria were as follows: (I) the minimum mean allele frequency (MAF) was $>0.05$; (II) the coefficient of link SNP linkage disequilibrium (LD) $\mathrm{r}^{2}$ was $>0.8$; (III) GWAS (Genome-wide association study, genome-wide association analysis) SNPs that had been reported were included in this study. Finally, eight SNPs of GLP-IR gene were detected in the present study, namely rs3765467, rs1042044, rs2268657, rs6923761, rs2268641, rs2295006, rs4714210 and rs10305420.

Amplification was achieved by multiplex PCR reaction. Each measurable allele locus ligated product was obtained after two ligation reactions. The raw data files were analyzed using GeneMapper software version 4.1 (Applied Biosystems, USA). A total of 884 postmenopausal women were analyzed.

\section{Statistical analysis}

Statistical analysis was performed using SPSS version 24.0 (IBM SPSS Statistics 24, USA). The continuous variables with normal distribution are expressed as mean \pm standard deviation $(\bar{x} \pm \mathrm{SD})$, and the variables with abnormal distribution as median and interquartile range. The continuous variables were compared with $t$-test between two groups; the chi-square test was used to compare the categorical variables. Haploview 4.2 was used to calculate 
Table 1 Baseline characteristics of subjects included in this study

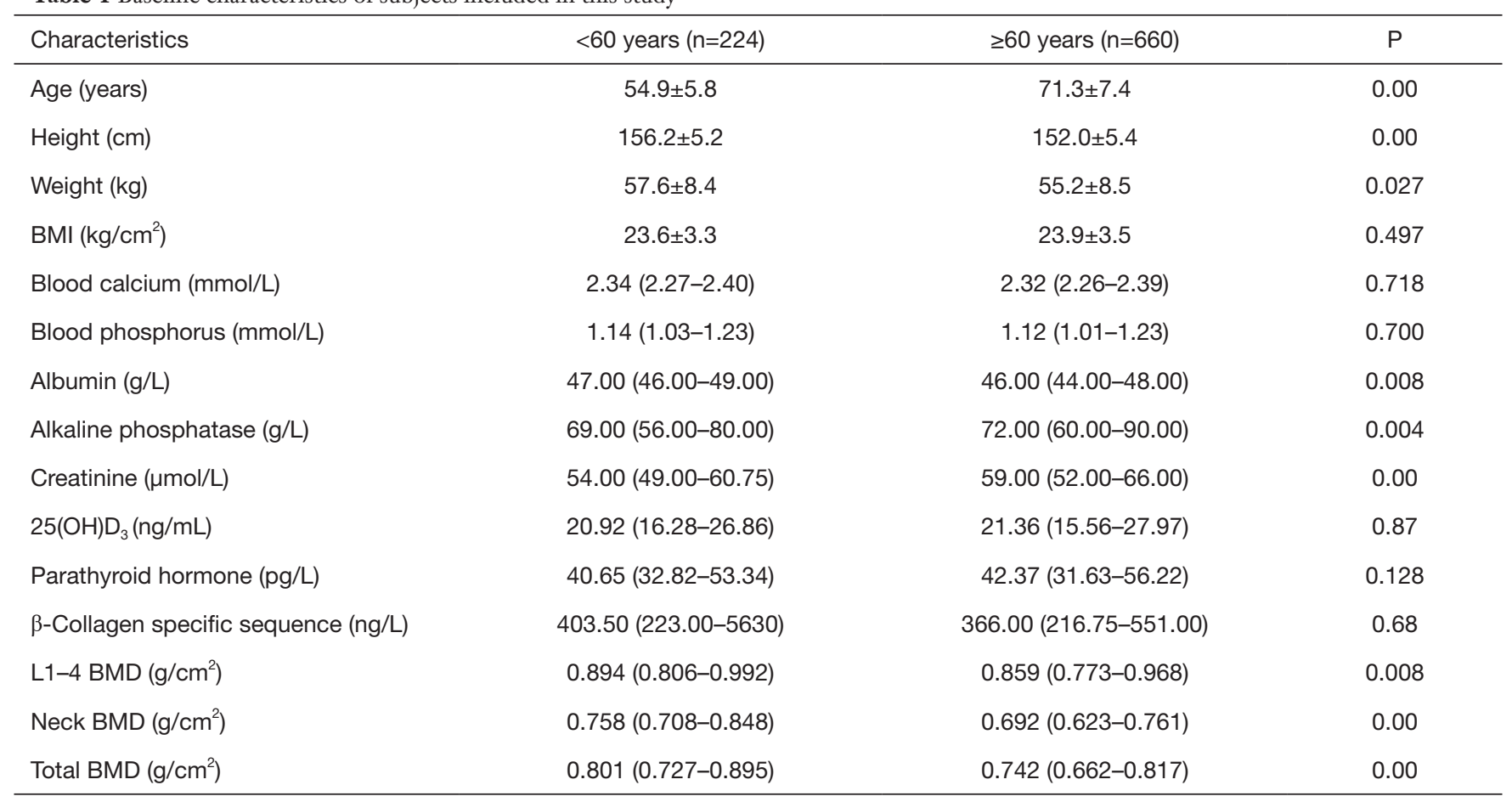

BMI, body mass index; BMD, bone mineral density; 25(OH)D3, 25-hydroxy vitamin D3; L1-4, lumbar vertebra 1-4.

the D' value and linkage disequilibrium coefficient $\left(\mathrm{r}^{2}\right)$ of the linkage disequilibrium (LD) between SNPs, and the haplotype region and corresponding haplotype were obtained. After adjustment for age, a linear regression model was employed to assess the relationship between GNP-1R SNPs, haplotypes and BMD of different sites in postmenopausal women. A value of $\mathrm{P}<0.05$ was considered statistically significant.

\section{Results}

\section{Characteristics of subjects}

A total of 907 postmenopausal women were included, but some subjects were excluded from this study because the samples were contaminated, had poor quality or were not successfully typed after one failure. Finally, 884 samples from postmenopausal women (mean age: $67.2 \pm 10.0$ years) were subjected to the detection of SNPs. In addition, subjects were divided into the $<60$ years group and the $\geq 60$ years group. The baseline characteristics of subjects included for the final analysis are shown in Table 1.

\section{Alleles frequency and haplotype}

In this study, eight SNPs were genotyped and analyzed. During the test, the detection of rs10305420 failed, and thus the remaining 7 SNPs were examined in which the minimum allele frequency (MAF) was greater than 0.01 . The genotype distribution met the Hardy-Weinberg equilibrium, and the MAF of 7 SNPs was similar to the genetic variation of Beijing Han population in China (CHBS) (Table 2).

The linkage disequilibrium Lewontin's D' value and linkage disequilibrium coefficient $r^{2}$ of 7 SNPs were further calculated. There was a strong linkage disequilibrium between 7 SNPs in this study $\left(0.908<\mathrm{D}^{\prime}<1\right)$. Thus, these 7 SNPs could be regarded as a linkage domain (Figure 1). Then, the haplotype and frequency in the linkage domain block were calculated, and results showed there were 15 haplotypes with the frequency greater than $1 \%$ in the linkage region (Table 3).

The relationship between 7 SNPs and BMD was further assessed in postmenopausal women. Results showed there was a correlation between rs2295006 and BMD at 
Table 2 Seven single nucleotide polymorphisms of glucagon-like peptide-1 receptor gene

\begin{tabular}{lcccccc}
\hline SNPs & Chr. position & SNP property & Alleles & HWE, P value & MAF in CHBS & MAF in this study \\
\hline rs2268657 & 39020542 & intron1 & C/T & 0.1902 & 0.34 & 0.326 \\
rs2295006 & 46182304 & nonsynon_exon2 & G/A & 0.7755 & 0.07 & 0.255 \\
rs3765467 & 46182304 & nonsynon_exon4 & G/A & 0.5521 & 0.23 & 0.01 \\
rs6923761 & 39055485 & nonsynon_exon5 & G/A & 1 & 0.47 & 0.01 \\
rs1042044 & 39041502 & nonsynon_exon7 & C/A & 1 & 0.39 & 0.46 \\
rs2268641 & 39050266 & intron12 & C/T & 0.5249 & 0.147 \\
rs4714210 & 39055485 & 3'-UTR_exon13 & G/A & 0.1432 & 0.317 & 0.29 \\
\hline
\end{tabular}

SNP, single nucleotide polymorphism; HWE, Hardy-Weinberg equilibrium; CHBS, Beijing Han population in China; MAF, minimum allele frequency.

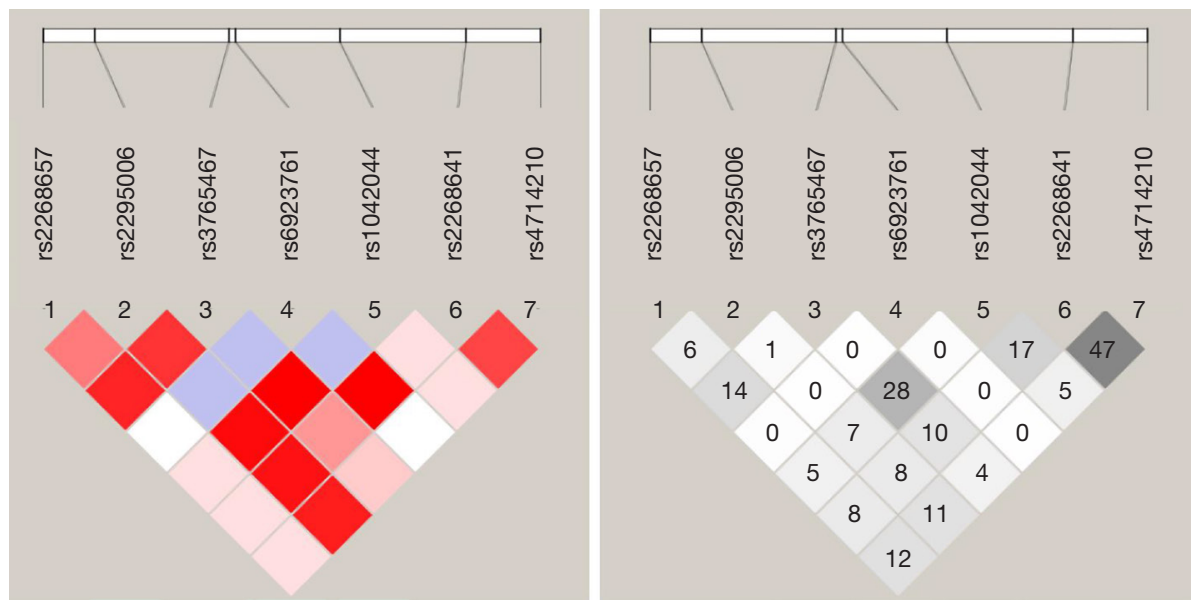

Figure 1 Chain transfer imbalance map of seven single nucleotide polymorphism of glucagon-like peptide-1 receptor gene.

specific site (Table 4). The A/A genotype of rs2295006 was negatively related to lumbar vertebrae $1-4 \mathrm{BMD}(\mathrm{P}<0.05)$. There is a negative correlation between rs2295006 and BMD of lumbar vertebrae and total hip (Table 5).

The linear regression analysis was employed to evaluate the correlation between 15 haplotypes and BMD. Results showed haplotypes had no relationships with the age, height, weight and body mass index (BMI) $(\mathrm{P}>0.05)$. A close correlation was noted between haplotypes CGAGCCA/ CGGGCTA and lumbar vertebrae 1-4 BMD (Table 6).

The haplotype CGAGCCA was negatively related to the lumbar vertebrae 1-4 BMD ( $\mathrm{P}=0.048)$. There was a negative correlation between haplotype CGAGCCA and lumbar vertebrae 1-4 BMD (Table 7).

The haplotype CGGGCTA was positively related to the lumbar vertebrae $1-4 \mathrm{BMD}(\mathrm{P}=0.001)$. There was a positive correlation between haplotype CGGGCTA and lumbar vertebrae 1-4 BMD (Table 7).

\section{Discussion}

Genome wide association studies (GWAS) have confirmed that BMD is associated with multiple genetically susceptible regions $(25,26)$. The association between vitamin $\mathrm{D}$ receptor gene polymorphism and osteoporosis was first reported by Morrison et al. in 1994 (27). Since then, more than 100 genetic polymorphisms have been identified to be associated with bone metabolism regulation, including sex hormones and their receptors, bone matrix componentrelated proteins and apolipoprotein $\mathrm{E}$ (ApoE). These findings suggest the important role of genetic factors in the pathogenesis of primary osteoporosis. 
Table 315 haplotypes of 7 single nucleotide polymorphisms of glucagon-like peptide-1 receptor gene and their frequencies (>1\%)

\begin{tabular}{|c|c|c|c|c|c|c|c|c|c|c|c|c|c|c|c|}
\hline Index & 1 & 2 & 3 & 4 & 5 & 6 & 7 & 8 & 9 & 10 & 11 & 12 & 13 & 14 & 15 \\
\hline rs2268657 & $\mathrm{C}$ & C & $\mathrm{C}$ & $\mathrm{T}$ & $\mathrm{T}$ & $\mathrm{C}$ & $\mathrm{T}$ & C & C & C & $\mathrm{T}$ & C & $\mathrm{T}$ & $\mathrm{C}$ & $\mathrm{T}$ \\
\hline rs2295006 & $\mathrm{G}$ & $\mathrm{G}$ & $\mathrm{G}$ & $\mathrm{G}$ & $\mathrm{G}$ & $\mathrm{G}$ & $\mathrm{G}$ & $\mathrm{G}$ & $\mathrm{G}$ & $\mathrm{G}$ & $\mathrm{G}$ & $\mathrm{G}$ & $A$ & A & $\mathrm{G}$ \\
\hline rs6923761 & $\mathrm{G}$ & $\mathrm{G}$ & $\mathrm{G}$ & $\mathrm{G}$ & $\mathrm{G}$ & $\mathrm{G}$ & $\mathrm{G}$ & $\mathrm{G}$ & $\mathrm{G}$ & $\mathrm{G}$ & $\mathrm{G}$ & $\mathrm{G}$ & $\mathrm{G}$ & $\mathrm{G}$ & $\mathrm{G}$ \\
\hline rs1042044 & C & A & $\mathrm{C}$ & A & $\mathrm{C}$ & $A$ & A & $A$ & C & C & C & C & $A$ & A & $A$ \\
\hline rs4714210 & A & A & A & A & A & $A$ & $\mathrm{G}$ & A & $\mathrm{G}$ & $\mathrm{G}$ & $\mathrm{G}$ & A & $\mathrm{G}$ & $\mathrm{G}$ & $A$ \\
\hline Frequency & 0.175 & 0.104 & 0.094 & 0.080 & 0.067 & 0.065 & 0.063 & 0.057 & 0.044 & 0.042 & 0.033 & 0.028 & 0.022 & 0.018 & 0.010 \\
\hline
\end{tabular}

Table 4 Relationship between glucagon-like peptide-1 receptor single nucleotide polymorphisms and BMD in the postmenopausal women

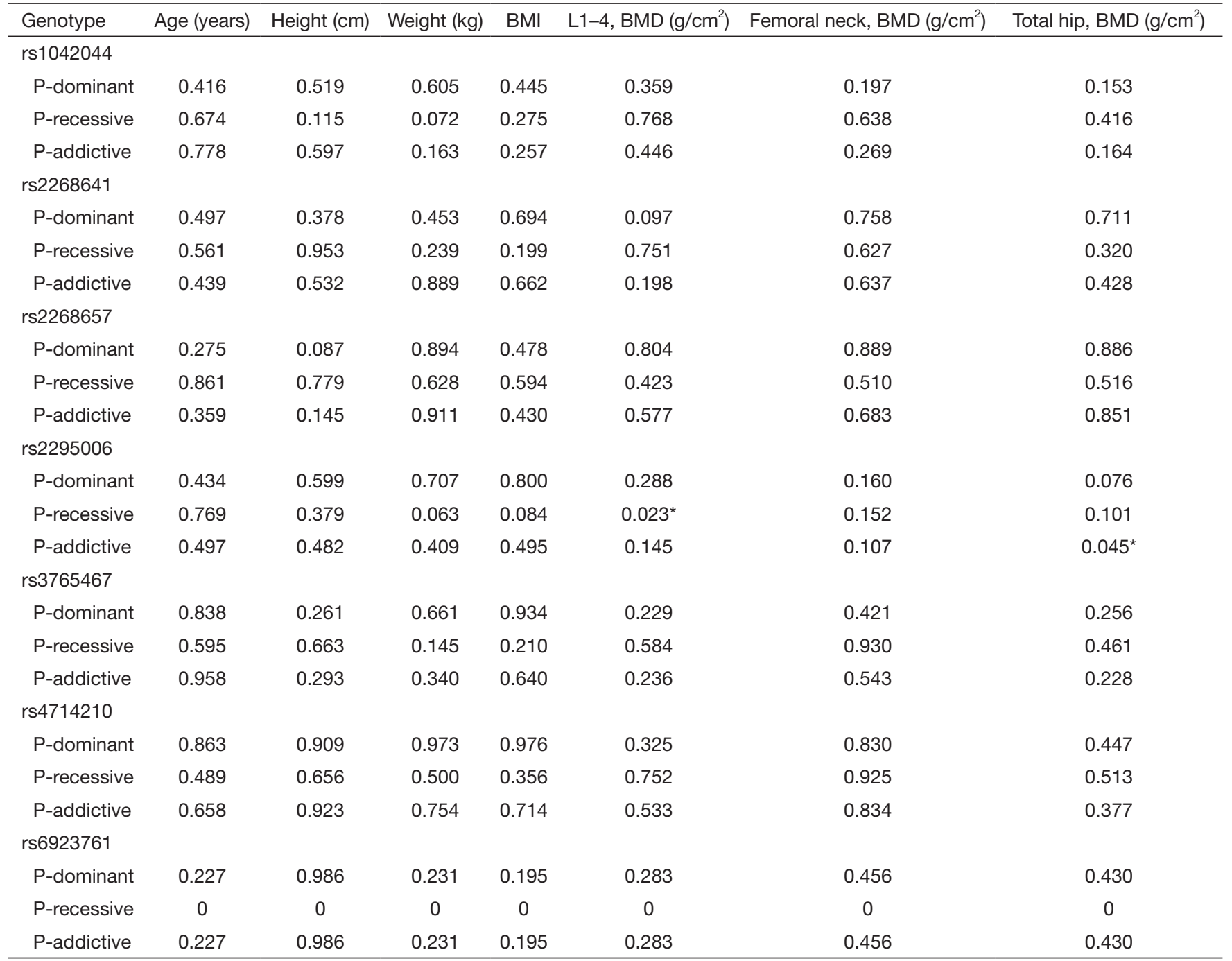

*, P $\leq 0.05$. BMD, bone mineral density; BMI, body mass index; L1-4, lumbar vertebra 1-4. 
Table 5 Correlation between glucagon-like peptide-1 receptor single nucleotide polymorphisms rs2295006 and BMD

\begin{tabular}{|c|c|c|c|c|c|c|}
\hline \multirow{2}{*}{ BMD } & \multicolumn{2}{|c|}{ Dominant } & \multicolumn{2}{|c|}{ Recessive } & \multicolumn{2}{|c|}{ Addictive } \\
\hline & $\beta$ & $P$ & $\beta$ & $\mathrm{P}$ & $\beta$ & $P$ \\
\hline L1 & -0.035 & $0.031^{*}$ & 0.057 & 0.453 & -0.029 & 0.060 \\
\hline L2 & -0.021 & 0.244 & -0.067 & 0.428 & -0.021 & 0.209 \\
\hline L3 & -0.007 & 0.730 & 0.086 & 0.367 & -0.003 & 0.885 \\
\hline L4 & -0.013 & 0.538 & -0.102 & 0.290 & -0.015 & 0.429 \\
\hline L1-2 & -0.018 & 0.527 & -0.177 & 0.179 & -0.023 & 0.387 \\
\hline L1-3 & -0.037 & 0.240 & -0.348 & $0.019^{*}$ & -0.047 & 0.114 \\
\hline L1-4 & -0.035 & 0.288 & -0.354 & $0.023^{*}$ & -0.045 & 0.145 \\
\hline L2-3 & -0.055 & 0.057 & -0.383 & $0.005^{\star \star}$ & -0.064 & $0.018^{\star}$ \\
\hline L2-4 & -0.054 & 0.077 & -0.388 & $0.007^{* *}$ & -0.064 & $0.027^{*}$ \\
\hline L3-4 & -0.061 & $0.025^{\star}$ & -0.432 & $0.001^{\star \star}$ & -0.071 & $0.005^{\star \star}$ \\
\hline Neck & -0.018 & 0.160 & -0.087 & 0.205 & -0.019 & 0.107 \\
\hline Wards & -0.03 & $0.027^{\star}$ & -0.13 & 0.137 & -0.032 & $0.013^{\star}$ \\
\hline Troch & -0.016 & 0.185 & -0.051 & 0.393 & -0.016 & 0.154 \\
\hline Inter & -0.037 & $0.034^{\star}$ & -0.164 & 0.123 & -0.039 & $0.016^{\star}$ \\
\hline Total & -0.025 & 0.076 & -0.108 & 0.175 & -0.026 & $0.045^{*}$ \\
\hline
\end{tabular}

${ }^{*}, \mathrm{P} \leq 0.05 ;{ }^{*}, \mathrm{P} \leq 0.01$. BMD, bone mineral density; L, lumbar vertebra; $\beta$, regression coefficient.

It has been confirmed that the bone resorption experiences a circadian change which may be related to the secretion of incretin after eating (28). Animal studies have revealed that, in case of intake of the same energy and the same compositions of carbohydrate, protein, and fat, the BMD of rats with high frequency of food intake (more than once daily) was significantly higher than that of rats with food intake once daily (29). In addition, patients with longterm total parenteral nutrition ( $>3$ months) often develop bone pain, hypercalciuria and elevated serum alkaline phosphatase (30). Blood calcium, blood phosphorus, 25 -hydroxy vitamin $\mathrm{D}$ and parathyroid hormone remained normal. These findings were subsequently confirmed by many studies (31). Many investigators have therefore proposed the concept of "entero-osseous axis" (32), which means that bone metabolism may be regulated by incretin.

GLP-1 is a type of incretin, and human bone marrow mesenchymal stem cells can express GLP-1R (33). In the GLP-1 $1 \mathrm{R}^{-/}$mouse model (16), the risk for osteoporosis increases significantly. In rats with type 2 diabetes mellitus (T2DM) and insulin-resistance (34), subcutaneous injection
Table 6 Relationship between 15 haplotypes of 7 single nucleotide polymorphisms of glucagon-like peptide-1 receptor gene and BMD in the postmenopausal women (linear regression analysis)

\begin{tabular}{|c|c|c|c|c|c|c|}
\hline \multirow{2}{*}{ Haplotype } & \multicolumn{2}{|c|}{ L1-4 BMD } & \multicolumn{2}{|c|}{ Neck BMD } & \multicolumn{2}{|c|}{ Total BMD } \\
\hline & $\beta$ & $P$ & $\beta$ & $P$ & $\beta$ & $P$ \\
\hline CGAGCCA & -0.037 & $0.048^{\star}$ & 0.003 & 0.652 & 0.007 & 0.400 \\
\hline CGGGACA & -0.002 & 0.922 & -0.001 & 0.919 & -0.004 & 0.685 \\
\hline CGGGCCA & 0.012 & 0.647 & 0.008 & 0.429 & 0.005 & 0.619 \\
\hline TGGGACA & -0.003 & 0.920 & -0.007 & 0.514 & -0.004 & 0.748 \\
\hline TGGGCCA & 0.052 & 0.086 & 0.000 & 0.999 & 0.008 & 0.546 \\
\hline CGGGATA & 0.007 & 0.807 & -0.009 & 0.453 & -0.009 & 0.499 \\
\hline TGGGATG & -0.017 & 0.590 & 0.010 & 0.399 & 0.008 & 0.532 \\
\hline CGGGATG & 0.003 & 0.915 & 0.004 & 0.742 & 0.001 & 0.945 \\
\hline CGGGCTG & -0.004 & 0.910 & -0.013 & 0.356 & -0.018 & 0.271 \\
\hline CGAGCTG & 0.013 & 0.732 & -0.010 & 0.483 & -0.006 & 0.701 \\
\hline TGGGCTG & 0.007 & 0.867 & -0.008 & 0.637 & -0.019 & 0.292 \\
\hline CGGGCTA & 0.154 & $0.001^{* *}$ & 0.012 & 0.516 & 0.007 & 0.730 \\
\hline TAGGATG & -0.082 & 0.090 & -0.024 & 0.197 & -0.037 & 0.071 \\
\hline CAGGATG & 0.043 & 0.449 & -0.010 & 0.651 & -0.011 & 0.641 \\
\hline TGGGATA & 0.041 & 0.589 & -0.005 & 0.867 & 0.015 & 0.643 \\
\hline
\end{tabular}

*, $\mathrm{P} \leq 0.05 ;{ }^{* *}, \mathrm{P} \leq 0.01$. BMD, bone mineral density; L1-4, lumbar vertebra $1-4 ; \beta$, regression coefficient.

of GLP-1 enhanced bone synthesis in an insulin independent manner. It is speculated that this enhancement of bone synthesis may be related to the increase in OPG/RANKL ratio. In addition, dyslipidemia has been identified as a major risk factor for osteoporosis-related fractures $(35,36)$. Most patients with osteoporosis will develop hyperlipidemia $(20,37)$. In rats fed with high fat, results showed GLP1 reversed the reduction of bone mass secondary to hyperlipidemia (21). The above findings suggest that the lack of GLP-1 may adversely affect the bone metabolism, and supplementation with GLP-1 can improve bone metabolism to a certain extent.

To date, only a few studies have investigated the effects of GLP-1R SNPs on the bone metabolism. In a Chinese study (38), the relationship between GLP-1R SNPs and BMD was investigated in 427 male core families. The six SNPs (rs2295006, rs3765468, rs6923761, rs1126476, rs1042044andrs3765467) were detected in this study, and results showed no correlation between genotypes and BMD. However, rs1042044 and rs3765467 are quantitative 
Table 7 Correlation between haplotype CGAGCCA/CGGGCTA and BMD

\begin{tabular}{|c|c|c|c|c|}
\hline \multirow{2}{*}{ BMD } & \multicolumn{2}{|c|}{ CGAGCCA } & \multicolumn{2}{|c|}{ CGGGCTA } \\
\hline & $\beta$ & $\mathrm{P}$ & $\beta$ & $\mathrm{P}$ \\
\hline L1 & -0.012 & 0.200 & 0.048 & $0.034^{*}$ \\
\hline L2 & -0.010 & 0.337 & 0.072 & $0.004^{\star *}$ \\
\hline L3 & -0.025 & $0.032^{*}$ & 0.055 & $0.049^{*}$ \\
\hline L4 & -0.017 & 0.153 & 0.072 & $0.012^{*}$ \\
\hline L1-2 & -0.026 & 0.097 & 0.124 & $0.001^{* *}$ \\
\hline L1-3 & -0.034 & 0.057 & 0.142 & $0.001^{* *}$ \\
\hline L1-4 & -0.037 & $0.048^{*}$ & 0.154 & $0.001^{* *}$ \\
\hline L2-3 & -0.040 & $0.017^{*}$ & 0.120 & $0.003^{\text {** }}$ \\
\hline L2-4 & -0.041 & $0.020^{*}$ & 0.132 & $0.002^{\star \star}$ \\
\hline L3-4 & -0.017 & 0.261 & 0.102 & $0.007^{\star *}$ \\
\hline Neck & 0.003 & 0.652 & 0.012 & 0.516 \\
\hline Wards & 0.007 & 0.393 & 0.003 & 0.868 \\
\hline Troch & 0.008 & 0.269 & 0.011 & 0.537 \\
\hline Inter & 0.009 & 0.367 & 0.000 & 0.986 \\
\hline Total & 0.007 & 0.400 & 0.007 & 0.730 \\
\hline
\end{tabular}

*, $\mathrm{P} \leq 0.05 ;{ }^{* *}, \mathrm{P} \leq 0.01$. BMD, bone mineral density; L, lumbar vertebra; $\beta$, regression coefficient.

trait loci for male lean tissue and adipose tissue mutations, respectively. The GLP-1R SNPs were significantly associated with the lean tissue and adipose tissue, suggesting that GLP-1R SNPs may indirectly affect BMD.

However, the association between GLP-1R SNPs and osteoporosis in postmenopausal women is still poorly understood. In the present study, eight SNPs of GLP-1R gene were detected according to previously reported, and the relationship between GLP-1R SNPs and BMD was further analyzed.

Our results showed, in 884 postmenopausal women, the A/A genotype of rs2295006 was negatively related to lumbar vertebrae $1-4 \mathrm{BMD}(\mathrm{P}<0.05)$, and allele $\mathrm{A}$ was negatively related to total hip BMD $(\mathrm{P}<0.05)$. That is, for rs2295006, only the homozygous genotype of A/A mutation had a negative correlation with lumbar vertebrae 1-4 BMD, and the negative correlation between locus and total hip BMD increases with the increase of allele $\mathrm{A}$ in a specific population. Therefore, in a specific individual, the rs2295006 of GLP-1R gene appears to be a homozygous
A/A mutant, which may result in decreased BMD in the lumbar vertebrae and total hip. In a specific population (such as Shanghai), if the frequency of the GLP-1R SNP rs2295006 allele A is higher, the BMD of lumbar vertebrae and total hip will be lower. Therefore, the allele A of GLP$1 \mathrm{R}$ rs2295006 predicts a decrease in BMD.

Of 15 haplotypes of 7 SNPs, a correlation between haplotype CGAGCCA/CGGGCTA and BMD was observed. There was a negative correlation between haplotype CGAGCCA and lumbar vertebrae BMD. The presence of haplotype CGAGCCA in the linkage domain may predicts a decrease in the lumbar vertebrae 1-4 $\mathrm{BMD}$. There was a positive correlation between haplotype CGGGCTA and lumbar vertebrae BMD. That is, the presence of haplotype CGGGCTA in the linkage domain predicts an increased BMD of the lumbar vertebrae 1-4.

It has been reported that many SNPs may not directly induce the expression of disease related genes. However, they are close to certain disease genes and thus may become important markers of some diseases. These SNPs are also known as tag SNPs. The genetically determinant SNPs can affect the phenotype of some diseases and it is necessary to investigate the corresponding functions. In our study, results showed the A/A genotype of rs2295006had a negative correlation with lumbar vertebrae $1-4 \mathrm{BMD}$. It can be regarded as a tag SNP and a determinant site associated with BMD may be close to it. This determinant site may be positively or negatively related to the BMD. This also suggests that rs2295006 can be used as a tag SNP to study multiple SNPs close to it.

In recent years, some studies have been conducted to investigate the biological effects of GLP-1R SNPs. Some studies have shown GLP-1R SNPs have a positive correlation with T2DM, islet cell function and obesity in different populations (39-42). Ma et al. (39) proposed that, in Han Chinese patients with T2DM, GLP-1R SNPs were associated with the risk of coronary heart disease. The GG genotype of rs 4714210 predicted a lower risk of coronary heart disease as compared to the AA genotype $(\mathrm{ORa}=0.475$, $\mathrm{CIa}=0.232-0.970, \mathrm{pa}=0.041)$, and could also reduce the severity of atherosclerotic lesions (43). Therefore, the GLP1R SNPs can be used as a predictor of risk for coronary heart disease in T2DM. In a Chinese study, the GLP-1R SNP rs2268657 was found to be associated with T2DM, which is mainly caused by the insufficient insulin secretion (40). In addition, rs3765467 significantly affected the response of islet B cells after infusion of GLP-1 in healthy individuals (41). Therefore, the GLP-1R SNPs may be used to guide 
the therapeutic use of GLP-1R agonists. In addition, the rs2268641 of GLP-1R gene is associated with obesity in European Americans (42), and the rs6923761 of GLP-1R gene is closely related to the fasting serum GLP-1 level in newly diagnosed T2DM patients (44). Further investigation on obese patients with polycystic ovary syndrome (45) revealed that rs6923761 and rs10305420 of GLP-1R gene are associated with the therapeutic efficacy of GLP-1R agonists.

Recent studies have shown that GLP-1 is able to regulate the bone metabolism (46). In the present cross-sectional study, the correlation between GLP-1R SNPs and BMD was investigated in postmenopausal women. Our results showed A/A genotype and haplotype CGAGCCA of rs2295006 were negatively related to BMD, suggesting that this SNP may negatively regulate bone metabolism. There was a positive correlation between haplotype CGGGCTA and lumbar vertebrae BMD, and this mutation enhanced its positive correlation with BMD. There were several limitations in our study. Only 7SNPs of GLP-1Rwere detected in our study and they could not represent all the GLP-1R SNPs in the postmenopausal women. Thus, the effects of otherGLP-1R SNPs on the BMD in the postmenopausal women cannot be excluded. The sample size is relatively small, and subjects were included from a local region, which limit the expansion of our findings. Thus, more prospective studies with large sample size are needed to confirm our findings.

\section{Conclusions}

In summary, our study indicates a correlation between GLP-1R SNPs and BMD in the postmenopausal women. The GLP-1R SNPs can be used to guide the assessment of metabolic diseases and the treatment of osteoporosis in the postmenopausal women. However, the specific mechanism underlying the relationship betweenGLP-1R SNPs and $\mathrm{BMD}$ is needed to be further studied.

\section{Acknowledgments}

Funding: This study was supported by the Pudong New Area Health and Family Planning Commission Fund Project (PWZzk2017-12).

\section{Footnote}

Conflicts of Interest: All authors have completed the ICMJE uniform disclosure form (available at http://dx.doi. org/10.21037/apm-19-396). The authors have no conflicts of interest to declare.

Etbical Statement: The authors are accountable for all aspects of the work in ensuring that questions related to the accuracy or integrity of any part of the work are appropriately investigated and resolved. The study was approved by the Ethics Committee of the Sixth People's Hospital, Shanghai Jiaotong University [2014-KY-001(K)].

Open Access Statement: This is an Open Access article distributed in accordance with the Creative Commons Attribution-NonCommercial-NoDerivs 4.0 International License (CC BY-NC-ND 4.0), which permits the noncommercial replication and distribution of the article with the strict proviso that no changes or edits are made and the original work is properly cited (including links to both the formal publication through the relevant DOI and the license). See: https://creativecommons.org/licenses/by-nc-nd/4.0/.

\section{References}

1. Association $\mathrm{OaBMDBoCM}$. Guideline for the diagnosis and treatment of Primary osteoporosis (2011). Chinese Journal of Osteoporosis and Bone Mineral Research 2011;04:2-17.

2. Montazeri-Najafabady N, Dabbaghmanesh MH, Mohammadian Amiri R, et al. Influence of Estrogen Receptor Alpha Polymorphism on Bone Mineral Density in Iranian Children. Hum Hered 2019;84:82-9.

3. Ensrud KE, Crandall CJ. Osteoporosis. Ann Intern Med 2017;167:ITC17-32.

4. Okazaki R. Management of osteoporosis in diabetes mellitus. Nihon Rinsho 2009;67:1003-10.

5. Kanazawa I. Diabetes-related osteoporosis. Nihon Rinsho 2015;73:1718-22.

6. Hayes JS, Coleman CM. Diabetic Bone Fracture Repair: A Progenitor Cell-Based Paradigm. Curr Stem Cell Res Ther 2016;11:494-504.

7. Bai YY, Peng XG, Wang BH, et al. Effects of stem cell microenvironment on bone marrow-derived endothelial progenitor cells from diabetic mice. Exp Clin Cardiol 2014;20:1057-68.

8. Piscitelli P, Neglia C, Vigilanza A, et al. Diabetes and bone: biological and environmental factors. Curr Opin Endocrinol Diabetes Obes 2015;22:439-45.

9. Strotmeyer ES, Cauley JA, Schwartz AV, et al. Diabetes is associated independently of body composition with 
$\mathrm{BMD}$ and bone volume in older white and black men and women: The Health, Aging, and Body Composition Study. J Bone Miner Res 2004;19:1084-91.

10. Danielson KK, Elliott ME, LeCaire T, et al. Poor glycemic control is associated with low BMD detected in premenopausal women with type 1 diabetes. Osteoporos Int 2009;20:923-33.

11. Yamamoto M, Yamaguchi T, Yamauchi M, et al. Diabetic patients have an increased risk of vertebral fractures independent of $\mathrm{BMD}$ or diabetic complications. J Bone Miner Res 2009;24:702-9.

12. Kasahara T, Imai S, Kojima H, et al. Malfunction of bone marrow-derived osteoclasts and the delay of bone fracture healing in diabetic mice. Bone 2010;47:617-25.

13. Gusova A, Pavlova M, Melnichenko G, et al. Bone mineral density in diabetic postmenopausal women with bone fracture. Eur Soc Endocrinol 2012;29:135.

14. Guo Q. Healing of Bone Fracture in Type 1 Diabetic Rat Models: a Potential Gene Therapy Using Bone Morphogenetic Protein: University of Dundee; 2015.

15. Trujillo JM, Nuffer W. GLP-1 receptor agonists for type 2 diabetes mellitus: recent developments and emerging agents. Pharmacotherapy 2014;34:1174-86.

16. Yamada C, Yamada Y, Tsukiyama K, et al. The murine glucagon-like peptide-1 receptor is essential for control of bone resorption. Endocrinology 2008;149:574-9.

17. Meng J, Ma X, Wang N, et al. Activation of GLP-1 Receptor Promotes Bone Marrow Stromal Cell Osteogenic Differentiation through beta-Catenin. Stem Cell Reports 2016;6:579-91.

18. Ma X, Meng J, Jia M, et al. Exendin-4, a glucagonlike peptide-1 receptor agonist, prevents osteopenia by promoting bone formation and suppressing bone resorption in aged ovariectomized rats. J Bone Miner Res 2013;28:1641-52.

19. Donnelly D. The structure and function of the glucagonlike peptide-1 receptor and its ligands. Br J Pharmacol 2012;166:27-41.

20. Stojanovic OI, Lazovic M, Lazovic M, et al. Association between atherosclerosis and osteoporosis, the role of vitamin D. Arch Med Sci 2011;7:179-88.

21. Nuche-Berenguer B, Lozano D, Gutierrez-Rojas I, et al. GLP-1 and exendin-4 can reverse hyperlipidic-related osteopenia. J Endocrinol 2011;209:203-10.

22. Simó R, Hernández C. GLP-1R as a Target for the Treatment of Diabetic Retinopathy: Friend or Foe? Diabetes 2017;66:1453-60.

23. Zhang XY, He JW, Fu WZ, et al. Associations of Serum
Osteocalcin and Polymorphisms of the Osteocalcin Gene with Bone Mineral Density in Postmenopausal and Elderly Chinese Women. J Nutrigenet Nutrigenomics 2016;9:231-42.

24. Gao G, Zhang ZL, Zhang H, et al. Hip axis length changes in 10,554 males and females and the association with femoral neck fracture. J Clin Densitom 2008;11:360-6.

25. Rivadeneira F, Styrkarsdottir U, Estrada K, et al. Twenty bone-mineral-density loci identified by large-scale metaanalysis of genome-wide association studies. Nat Genet 2009;41:1199-206.

26. Styrkarsdottir U, Halldorsson BV, Gretarsdottir S, et al. Multiple genetic loci for bone mineral density and fractures. N Engl J Med 2008;358:2355-65.

27. Morrison NA, Qi JC, Tokita A, et al. Prediction of bone density from vitamin $\mathrm{D}$ receptor alleles. Nature 1994;367:284-7.

28. Hygum K, Starup-Linde J, Harsløf T, et al. The diurnal variation of bone formation is attenuated in adult patients with type 2 diabetes. Eur J Endocrinol 2019;181:221-31.

29. Li F, Muhlbauer RC. Food fractionation is a powerful tool to increase bone mass in growing rats and to decrease bone loss in aged rats: modulation of the effect by dietary phosphate. J Bone Miner Res 1999;14:1457-65.

30. Klein GL, Targoff CM, Ament ME, et al. Bone disease associated with total parenteral nutrition. Lancet 1980;2:1041-4.

31. Faienza MF, D'Amato E, Natale MP, et al. Metabolic Bone Disease of Prematurity: Diagnosis and Management. Front Pediatr 2019;7:143.

32. Christensen MB, Gasbjerg LS, Heimbürger SM, et al. GIP's involvement in the pathophysiology of type 2 diabetes. Peptides 2020;125:170178.

33. Sanz C, Vazquez P, Blazquez C, et al. Signaling and biological effects of glucagon-like peptide 1 on the differentiation of mesenchymal stem cells from human bone marrow. Am J Physiol Endocrinol Metab 2010;298:E634-43.

34. Nuche-Berenguer B, Moreno P, Esbrit P, et al. Effect of GLP-1 treatment on bone turnover in normal, type 2 diabetic, and insulin-resistant states. Calcif Tissue Int 2009;84:453-61.

35. Esposito K, Capuano A, Sportiello L, et al. Should we abandon statins in the prevention of bone fractures? Endocrine 2013;44:326-33.

36. García-Gavilán JF, Bulló M, Canudas S, et al. Extra virgin olive oil consumption reduces the risk of osteoporotic 
fractures in the PREDIMED trial. Clin Nutr 2018;37:329-35.

37. Mandal CC. High Cholesterol Deteriorates Bone Health: New Insights into Molecular Mechanisms. Front Endocrinol (Lausanne) 2015;6:165.

38. Xiang S-K. Associationsof GLP-1 and its receptor gene polymorphisms with parameters related to bone metabolism: Suzhou University; 2016.

39. Ma X, Lu R, Gu N, et al. Polymorphisms in the GlucagonLike Peptide 1 Receptor (GLP-1R) Gene Are Associated with the Risk of Coronary Artery Disease in Chinese Han Patients with Type 2 Diabetes Mellitus: A Case-Control Study. J Diabetes Res 2018;2018:1054192.

40. Zheng Y, Luo T, Zhao Y, et al. Correaltion betweenglucagon-like peptide 1 receptor gene polymorphism and type 2 diabetesin Shanghai patients. Chinese Journal of Endocrinology and Metabolism 2005;21:511-3.

41. Sathananthan A, Man CD, Micheletto F, et al. Common genetic variation in GLP1R and insulin secretion in response to exogenous GLP-1 in nondiabetic subjects: a

Cite this article as: Zhang L, He J, Sun X, Luo X, Zeng J, He W, Liu X, Feng B. Relationship between glucagon-like peptide- 1 receptor gene polymorphism and bone mineral density in postmenopausal women in Shanghai. Ann Palliat Med 2020;9(4):1732-1741. doi: 10.21037/apm-19-396 pilot study. Diabetes Care 2010;33:2074-6.

42. Li P, Tiwari HK, Lin WY, et al. Genetic association analysis of 30 genes related to obesity in a European American population. Int J Obes (Lond) 2014;38:724-9.

43. Ravassa S, Zudaire A, Diez J. GLP-1 and cardioprotection: from bench to bedside. Cardiovasc Res 2012;94:316-23.

44. de Luis DA, Aller R, Izaola O, et al. Role of rs6923761 gene variant in glucagon-like peptide 1 receptor in basal GLP-1 levels, cardiovascular risk factor and serum adipokine levels in naive type 2 diabetic patients. $\mathrm{J}$ Endocrinol Invest 2015;38:143-7.

45. Jensterle M, Pirs B, Goricar K, et al. Genetic variability in GLP-1 receptor is associated with inter-individual differences in weight lowering potential of liraglutide in obese women with PCOS: a pilot study. Eur J Clin Pharmacol 2015;71:817-24.

46. Ceccarelli E, Guarino EG, Merlotti D, et al. Beyond glycemic control in diabetes mellitus: effects of incretinbased therapies on bone metabolism. Front Endocrinol (Lausanne) 2013;4:73. 